Int. J. Electrochem. Sci., 16 (2021) Article ID: 210336

International Journal of

ELECTROCHEMICAL

SCIENCE

$\underline{\text { www.electrochemsci.org }}$

\title{
Corrosion Inhibition Effect of 5-Azidomethyl-8- Hydroxyquinoline on AISI 321 Stainless Steel in Phosphoric Acid Solution
}

\author{
Aimad Mazkour ${ }^{1}$, Souad El Hajjaji ${ }^{1,}{ }^{*}$, Najoua Labjar ${ }^{2}$, El Mostapha Lotfi ${ }^{2}$, Mohammed El Mahi ${ }^{2}$ \\ ${ }^{1}$ Laboratory of Spectroscopy, Molecular Modeling, Materials, Nanomaterials, Water and \\ Environment, CERN2D, Faculty of Sciences, Mohammed V University in Rabat, Morocco \\ ${ }^{2}$ Laboratory of Spectroscopy, Molecular Modeling, Materials, Nanomaterials, Water and \\ Environment, CERN2D, ENSET, Mohammed V University in Rabat, Morocco \\ *E-mail: selhajjaji@hotmail.com or souad.elhajjaji@um5.ac.ma
}

doi: $10.20964 / 2021.03 .03$

Received: 20 September 2020 / Accepted: 4 November 2020 / Published: 31 January 2021

In the present paper, 5-Azidomethyl-8-hydroxyquinoline (AMHQ), a synthesized molecule, has been evaluated as a corrosion inhibitor for AISI 321 stainless steel in $5.5 \mathrm{M}$ phosphoric acid solution, using chemical and electrochemical methods such as, hydrogen gas evolution, potentiostatic tests, potentiodynamic polarization, and impedance measurements (EIS). The obtained results show that the inhibition ability is enhanced with increasing concentrations of AMHQ and decreased with temperature. Potentiodynamic polarization curves showed that the AMHQ was acting as a mixed type inhibitor, by adsorption on both anodic and cathodic sites of Alloy 321. EIS measurements revealed that the dissolution of Alloy 321 is controlled by a mechanism of pure activation. The AMHQ is adsorbed on Alloy 321 surface according to the Langmuir isotherm adsorption model and thermodynamic parameters of the adsorption were also determined. Functional density theory (DFT) was used to modelize the interactions between the molecular structure of AMHQ and stainless steel surface.

Keywords: Corrosion; Inhibitor; Stainless steel; EIS; Phosphoric acid

\section{$\underline{\text { FULL TEXT }}$}

(C) 2021 The Authors. Published by ESG (www.electrochemsci.org). This article is an open access article distributed under the terms and conditions of the Creative Commons Attribution license (http://creativecommons.org/licenses/by/4.0/). 